\title{
Actions Speak Louder than Words: Stop Talking-Do! The Role of Social Psychology to turn Talkers into Doers to Nourish Organizational Behavior
}

\author{
Eddie John Paul Fisher \\ Faculty of Social Sciences, Universidad de Oriente, Santiago de Cuba, Cuba \\ Yorkys Santana González \\ Faculty of Social Sciences, Universidad de Oriente, Santiago de Cuba, Cuba \\ Eddie Fisher (Corresponding author) \\ 8 Kendal, Swindon, Wiltshire, SN5 8HW, United Kingdom \\ Tel: 44-179-349-0423 E-mail: eddie.fisher9@btinternet.com
}

Received: September 19, 2018 Accepted: October 9, 2018 Published: October 20, 2018

doi:10.5296/ber.v8i4.13666

URL: https://doi.org/10.5296/ber.v8i4.13666

\begin{abstract}
Effective and capable people are in high demand amongst businesses and educational establishments. Companies are not getting the best out of their people. It appears that there is a gap between what people are saying they are going to do and what they actually do. This research, based on a combination of what is already known about the subject matter under investigation and the practical experiences of research participants, investigated how this organizational behavior gap could be closed and what the potential benefits would be for both individuals and companies. The main focus of this research was to identify effective solutions how talkers could become doers and how talkers would benefit from adopting and applying the suggested recommendations how changes in attitude/behaviors and routines could lead to improved action-based capabilities. The outcome of this research suggests that the contributions made by this research can be measured through appropriate Key Performance Indicators (KPIs) to measure and demonstrate the effectiveness of considered performance improvements. It is suggested that the contributions from this research can be applied universally provided that cultural diversity is taken into consideration.
\end{abstract}


Keywords: Perception, Performance Improvement, Attitude and Behavior, Focus and Attention, Social Psychology, Organizational Behavior

\section{Introduction}

'Deus, dona mihi serenitatem accipere res quae non possum mutare, fortitudinem mutare res quae possum, atque sapientiam differentiam cognoscere' (God, grant me the serenity to accept the things I cannot change, the courage to change the things I can and the wisdom to know the difference)-Serenity Prayer (Reinhold Niebuhr)

Businesses and Educational Organizations such as Universities and Colleges are driven by increasingly volatile and competitive markets to perform better and provide more value for money. Economic upheavals affect all parts of an organisation, the work they do and ultimately, all their people. Change is inevitable and is likely to become the norm for the foreseeable future. Organizations are under pressure to optimise the efficiency and effectiveness of their work force to respond to these pressures positively. This is an enormous challenge and requires careful approaches as each individual's brain is wired differently so different reactions to change can be expected. People's inputs must be considered and their acceptance and buy in to planned changes is of paramount importance to success. This research considers one area that appears to have the potential to yield the highest possible return on investment in people: talkers and doers. There are two types of people at work (and, of course, private life): those who talk a lot and never get much done, heavily relying on others to get on with the doing, and those who do a lot, do not talk about it much and who will simply do what they say they are going to do, without even thinking about it.

It appears, in this context, that many people are not getting much done because they are not doing the right things or are not doing things right, in a timely manner. Talkers, typically, will put off what they say they will do only to find themselves running out of time. The result is that colleagues at work will lose interest after a while. They experience people repeating themselves time after time, for example, what they say they are going to do without seeing any positive results. Typical resistance to change attitudes and behaviors are: not seeing why there is a need to change how they work, finding excuses not to engage in the change process, appearing to be threatened by the change (s), cultural issues both at corporate and individual level or simply not supporting any change for the sake of it. It is individuals who do the thinking and who focus on developing prospective business winning ideas and opportunities for their respective business. Turning talkers into doers is dependent on the readiness and capability to change of any organization and their acquired levels of knowledge, skills and attitudes. The rewards will be a higher motivated work force, more satisfied customers and higher levels of Return on Investment (ROI) to satisfy, for example, key stakeholders including shareholders. This research investigates how phenomena can help to develop suggestions how talkers can become doers through the adoption of appropriate behaviors and changes to habits or routines.

The role of social psychology is considered as an aid to improve the social lives of people, and in the context of this research, how changes in behavior can lead to changes in capabilities, and ultimately, changes in beliefs and values. According to Fisher and Santana 


\section{MInstitute ${ }^{\text {Mink }}$}

Business and Economic Research

ISSN 2162-4860

2018, Vol. 8, No. 4

González (2013) attitudes influence how people think, what they value and how they view the world. It appears that there is a positive relationship between attitudes and behaviours and how levels of someone's competence can be increased through positive influences on these. This research further suggests that behaviour in itself is not so important but what the behaviour actually achieves is very important. Maio and Haddock (2010) suggest that attitudes are closely linked to behaviour. They consider that attitudes should predict behaviour. Behaviour is overt and can be observed. They define behaviour as an activity that covers, for example, how people act in accordance with their values, beliefs and attitudes towards people, things and institutions. Gill (2011) defines behavioural competences as the knowledge, skills and personal behaviours and characteristics that are associated with achieving corporate objectives. It appears that these are a popular method for predicting leadership success.

It appears that these impact on people's identity and could thus be the trigger point for effecting a metamorphosis from talking to doing. The outcome of this research demonstrates that if people change their habits/routines, for the right reasons, it is possible for them to become whoever they wish or need to be. It takes a positive mindset to achieve the desired results of the change. It will be necessary for people to understand that every human brain is wired differently (Fisher and Santana González, 2017). In reality, this means that 'one size does not fit all'. It will be necessary for talkers to think flexibly rather than give up at the first hurdle. Doers have a major role to play in this change process, too. They need to be considerate when engaging with talkers who wish to change and make allowances for talkers' shortfalls.

\subsection{Literature Review}

This literature review was limited to two areas considered to be most relevant for the purpose of this research, namely cognitive and neurological:

\subsubsection{Cognitive}

Stolier and Freeman (2016) argue that human beings have unique abilities to perceive and understand one another. People have and show good judgements about the identities, social categories, traits and minds of fellow human beings. These perceptions are computed and evaluated with high levels of accuracy, rapidly, automatically and simultaneously. The prefrontal cortex area of the brain is thought to have a role in a wide range of complex social-cognitive behaviours, including making inferences about what other people are thinking and processing information about the self (Crisp and Turner, 2010). Some research conducted by Mitchell et al. (2005) concluded that the prefrontal cortex is specifically used when trying to understand the attributes that other people possess but not for making more general judgements about others. Visual perceptions of others are shaped through people's context, culture, prior knowledge, emotional and motivational states. It appears that slight inaccuracies in perception could potentially 'facilitate adaptive behavior such as erring on the side of caution to rapidly avoid potentially dangerous stimuli' (Gibson, 1979, page 140). In the context of this research, 'talkers' could be impacted by those perceptions, beyond control, and see the outputs from discussions with 'doers' as a threat and react accordingly. Fisher and 
Santana González (2017) quote Johnson and de Haan (2015) who discuss that cognitive neuroscience studies in adults have revealed a network of structures involved in the perception and processing of social stimuli, including interpreting the thoughts and intentions of other humans. One of the major characteristics of the brain is its social nature. Adult people have areas of the brain specialized for processing and integrating sensory information about the appearance, behaviour and intentions of other humans. Mentalistic understanding of others' behaviour, the so-called theory of mind, has been associated with various neural structures, including the Amygdala (beyond the perception of faces, eyes and the actions of others, the developing child needs to develop neural and cognitive mechanisms for understanding the behaviour of others in terms of their intentions, goals and desires. The Amygdala is the integrative centre for emotions, emotional behaviour and motivation. It plays a primary role in the processing of memory, decision-making and emotional reactions.

According to Ambady et al. (2000), visual information relating to another person is overt and can be observed similar to human behavior. It can provide details of the current emotional state of another person, their beliefs and desires. These inferences of people's non-verbal behaviors can be picked up quickly and they appear to be highly accurate. Initial perceptions impact people's inferences, evaluations and behaviors toward others. Talkers, for example, can pick up specific face, body and voice cues of others and place people into identity and social category membership and mental states (Mc Aleer et al., 2014; Oosterhof and Todorov, 2008; Zebrowitz, 1997). Social information such as sex, race and age, social status and occupation helps people to group individuals. Stolier and Freeman consider that stereotypes are trait and behavioral ascriptions generalized to a social category such as talkers and doers. Once determined, people categorize others socially often without awareness (Macrae and Bodenhausen, 2000; Freeman and Ambady, 2011). Kelsey (2014) reports that perhaps the difference between people who do things and those who only talk, lies in the areas he refers to as motivation, drive and success. Kelsey's views are based on the outcomes of research carried out at Stanford University in the USA in 1972 with four-year old children. They were offered a choice of eating a marshmallow now or wait 15 minutes and get a second one. The outcome of this research was between 'defer gratification-and therefore develop productive future-oriented organizational competence, and those preferring impulse-driven instant gratification who were thus condemned to organizational incompetence and underachievement' (page 11).

According to Kelsey, if people believe that they are worthy of success (however measured), they adopt behaviors that prevent it. Self-esteem lies at the heart of the two key symptoms of people's unproductive state: procrastination and clutter. Both may involve some elements of self-sabotage because peoples' inner convictions regarding what they deserve. Kelsey suggests that people who have shortcomings or fail to achieve things, should not blame others or circumstances for these. People need to experience a 'realization' that it is up to individuals to make things happen. No one will do it for them: 'Anyone seeking productive organizational competence needs to experience something similar. Disorganization, procrastination, clutter, cynicism, even anger, depression and distrust: all are symptoms of a malaise of our own making in which our poor self-beliefs (however acquired) have been 
translated into disabling inactions or self-sabotaging actions' (page 45). Not dealing with these disabling attitudes and habits (fostered by people's self-beliefs), will enable these to hinder people to, for example, move from just talking to actually doing. Kelsey argues that the key to all this is motivation. Motivation regulates all behavior and without motivation people are going nowhere. Kelsey quotes Goleman (2007) who claims that people are motivated to do something whenever they do, pursue or achieve something. Motivation ignites, energizes, determines, directs and explains. Kelsey quotes Goleman (1995;1998) who states that people who do things (doers) work at their best when they are in a state of mind he refers to as 'flow'. It does not matter what kind of work people do-flow moves people to do their best work. With flow, there is no need for motivation, says Goleman. It is built in. People's fears are forgotten, their disappointment history and their creativity unleashed.

In contrast, Allen (2001) suggests that, generally, many people have lots of things to do and yet still keep a clear head and stay in relaxed control. For people to get on top of things and stay in control, they will need to apply many of the skills they already have, in a more timely, consistent and logical way. This allows people to be in control and not lose it. It appears that work today has no clear boundaries. This explains why much of the work people do is not always completed as intended, such as 'How good could the planned conference potentially be' or 'How productive was the staff meeting actually versus potentially could have been'? Allen considers that those who have a good balance and relaxation level are more likely to succeed in everything they do. It is the ability to clear the mind and being flexible. Allen refers to this perfect state of mind as 'Mind Like Water' (for example, responding to the force and mess of a pebble appropriately). For people to realise their wishes and desired outcomes, 'outcome thinking is one of the most effective means available for making wishes reality (page 15). Employing the human brain is part of getting things done. Allen argues that the human brain will not rest until all planned activities and thoughts have been properly clarified and stored in a system people are absolutely familiar with. It is a waste of time and energy to keep thinking about activities where no progress has been made. Managing actions is paramount to achieving desired results. Each action may only require a minute or two of people's time to make progress but clarifying things right at the beginning will allow people to reap the benefits of managing actions. Quest (1997) considers that it is implied that there are two different types of people: those who do things and improve themselves, and those who merely talk but not achieve much. Quest suggests that managers/teachers, for example, should determine first, for people they manage, what their staff value (where are they now and where do they want to be, Fig. 1). Values are things that are important to human beings. They underpin and influence people's behaviors and the way they react. It is important for people to understand the impact they have. The outcome of this exercise will be of value to both doers and talkers. By being conscious of their values, people can understand better their behavior and the stress and frustration they experience when their values are compromised. It is then possible for people to choose to adjust their life so that their values and the way they spend their time become more attuned. 


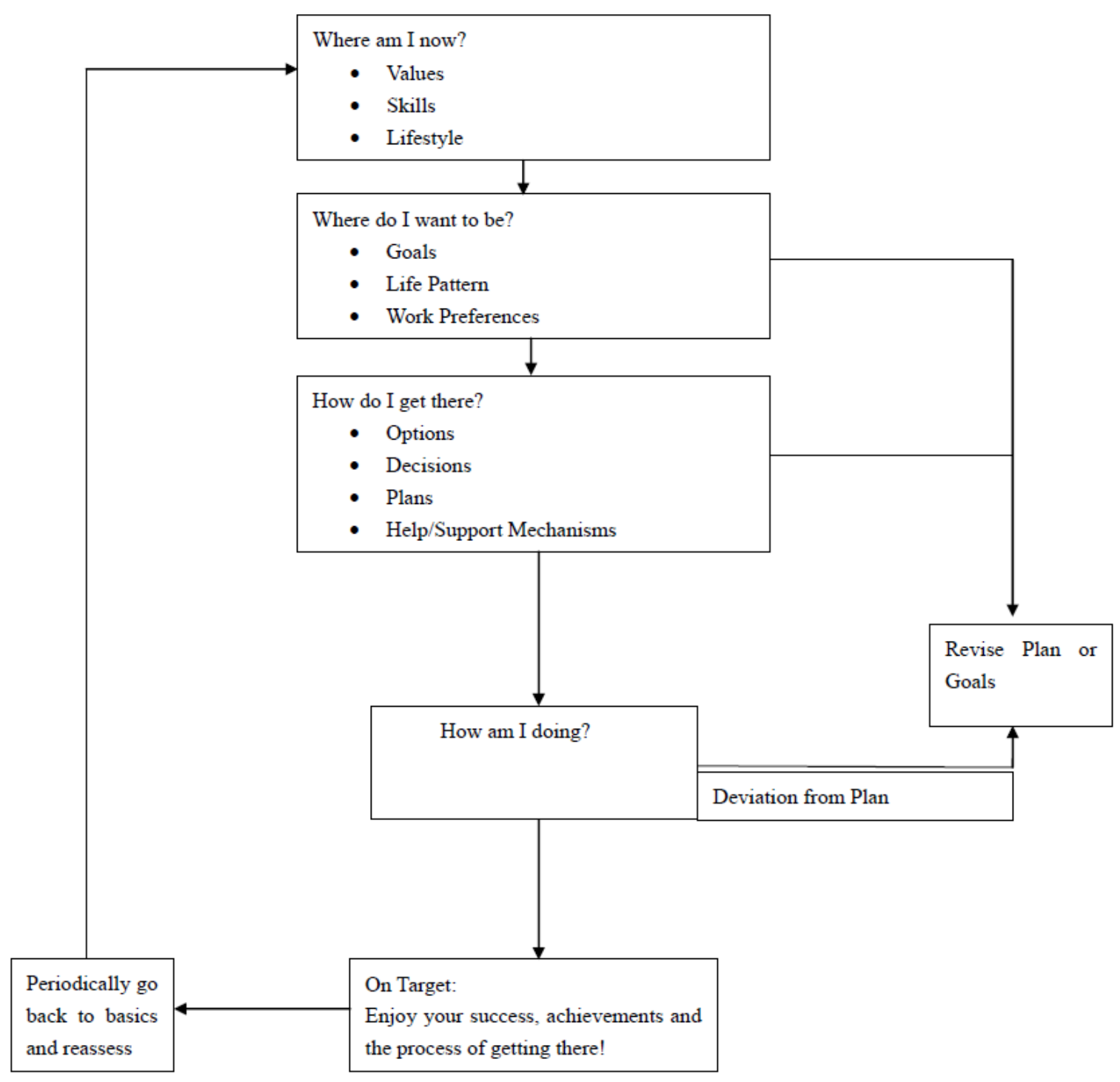

Figure 1. The Life and Career Planning Process (Quest, 1997)

Quest purports that dreams in themselves will not get people anywhere. Talkers appear to be in a constant dream-like state which would explain why they do not get much done. It is the translation of these dreams into goals, objectives and actions that makes them real. The following tools (Tables 1 and 2) can help to turn dreams or visions into reality:

Table 1. Define Your Goals (adapted from Quest, 1997

\begin{tabular}{|l|l|l|}
\hline 'Dream' Area & Goal & Objectives \\
\hline Teaching & To turn talkers into doers & $\begin{array}{l}\text { 1. To turn } 6 \text { talkers into doers by the end of the year } \\
\text { 2. To adopt a more proactive teaching/management } \\
\text { style by... }\end{array}$ \\
3ork & $\begin{array}{l}\text { To increase the productivity of } \\
\text { talkers }\end{array}$ & \\
\hline Environments & & \\
\hline
\end{tabular}


Table 2. Action Plan (adopted from Quest, 1997)

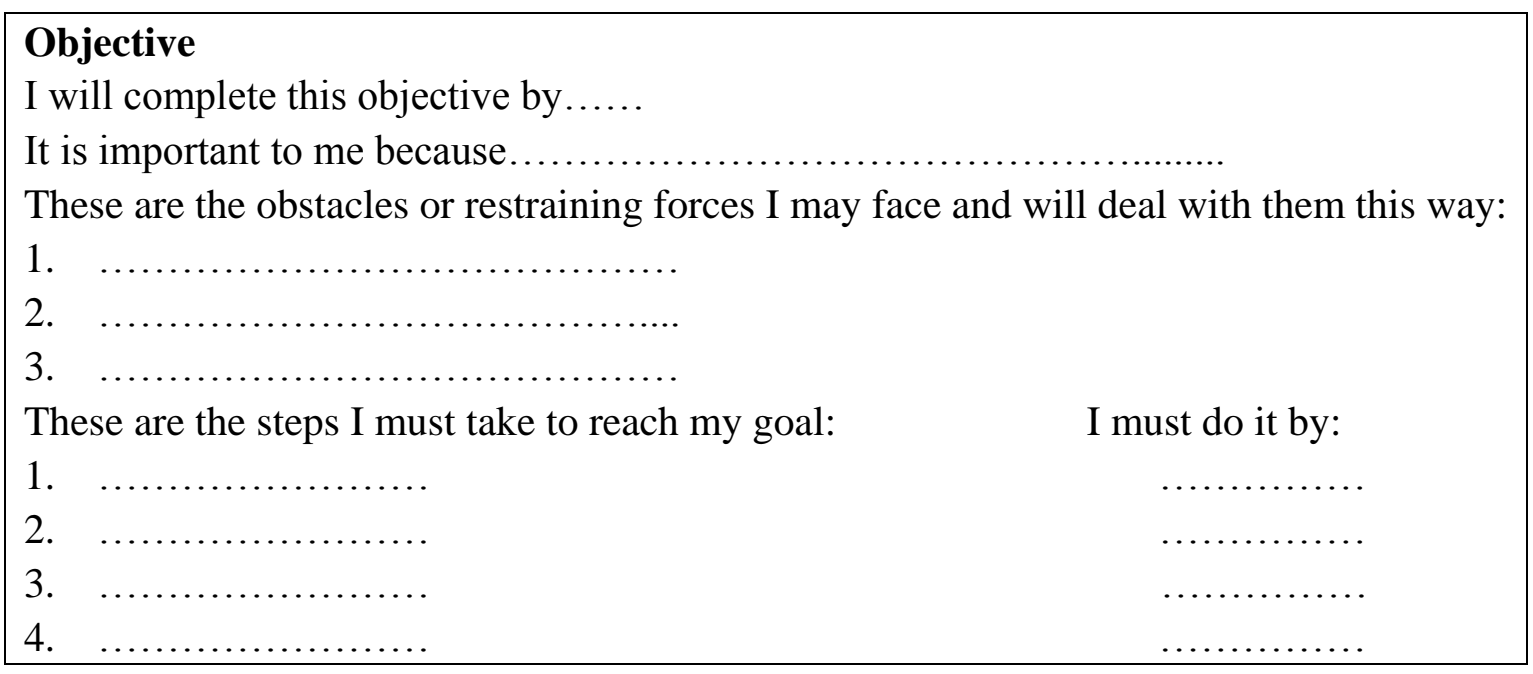

Mentoring is considered to be an effective way to help another person develop their own mindsets, ways of thinking and personal insights to create their own wisdom (Owen, 2011). In the context of this research, talkers need to integrate experience and reflection so they create a better understanding, for example, what progress they are making to talk less and do more. It helps them to recognize how, and in what situations, to make the best use of their personal strengths, attitudes and aptitudes. It advances their abilities to develop powerful and pragmatic approaches, for example, to manage any weaknesses that may get in the way of achieving intended habit/routine changes. According to Owen, improved decision-making is a by-product of this approach. Those who wish to change their habits/routines would benefit from developing their ability to extract insights from their experiences. It will help them to manage uncertainty and complexity in the absence of guidebooks. Mentors can assist talkers, for example, to enhance their levels of wisdom by being more willing to be curious and willing to learn more about their environments and other people: 'Mentoring is a powerful process for making sustainable progress based on the positive partnership of two people' (Owen, 2011, p. 3). The definition of mentoring adopted in the context of this research is: 'Mentoring supports a process that is about enabling, supporting, sometimes triggering, major change in people's life and work. As such, it is about developing the whole person, rather than training in particular skills' (Clutterbuck, 1991). Owen suggests that mentoring needs to achieve a change in thinking and ways of seeing things, including understanding how to learn and do things:

Practice-Do things differently

Learning-Understand how you learn

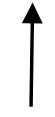

Behavior-Seeing things differently 
Cognitive-Change in Thinking

When mentoring is transformational and person-centred, it is a very powerful development approach, for example, at personal level (Clutterbuck, 1998)

\subsubsection{Neurological}

Dilts (1990) suggests that there are a number of neurological levels of change as far as human behavior is concerned. The role of each level is to bring together, organize and direct interactions from the level below. Dilt's five levels, in order of priority, are:

1 Identity-Basis sense of the self and people's core value

2 Beliefs and Values-It is what people believe in and value

3 Capabilities-This covers what people car capable of doing

4 Behavior-Behaviors are overt and show what people actually do

5 Environment-This is the context in which behaviors happen

According to Klein $(2014 ; 2017)$, performance improvement can be achieved by doing two things: reduce errors and increase insights (Fig. 2). People who do things, have opportunities to make mistakes thus gaining new insights. The same cannot be said for people who talk but do not do. Talkers can change: do more, learn from the insights of mistakes and grow as a person.

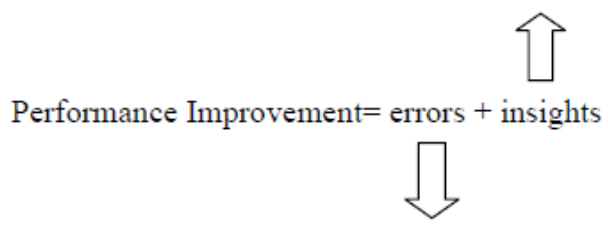

Figure 2. Mistakes v Insights (Klein, 2014; 2017)

Klein quotes Walls (1926) who developed a four-stage model of insight. During the preparation stage, a problem is investigated but despite rigorous efforts remains fruitless. The incubation stage allows the subconscious to take over, stopping any conscious thinking. Mental relaxation aids this process. Next comes the illumination stage when insights emanate from out of nowhere, suddenly and with absolute immediate certainty. The final stage, verification, allows people to test if any ideas are valid. Klein suggests caution not to follow this model blindly and for all occasions. Deliberate and specific preparation does not guarantee success. Fisher and Santana González (2017) report that each person's brain works differently due to prevailing experiences each person has. It is imperative to take this into account when considering applying brain power to engage in mental activities. Klein argues that people make recognitional decisions that depend on decades of experience to build up hundreds of thousands of patterns. People quickly seize up situations and recognise the option most likely to work. It appears that, based on practical experiences, doers are more likely to develop new insights than people who simply talk. Based on some extensive 
research on how people's habits develop and work, Duhigg (2012) reports that habits can be overridden by new habits, or as Duhigg refers to them, neurological patterns. This remarkable revelation was discovered by a scientist examining a volunteer's brain. As the volunteer's habits changed, so had the volunteer's brain.

By focusing on one neurological pattern, known as a keystone habit, the volunteer had been able to re-programme her life routines. The region closes to her forehead showed new activities. It is generally believed by scientists that this is the region behavioral inhibition and self-discipline start.

The volunteer, in fact, helped scientists to understand how a decision becomes an automatic behavior. Duhigg suggests that routines occur by habit. According to scientists, habits emerge because the brain is constantly looking for ways to save effort. It appears that this process within the human brain is a three-step loop (Fig.3):

1. Cue-tells the brain to go into automatic mode and which habit to use

2. Routine-can be physical, mental or emotional

3. Reward-helps the brain to decide if this particular loop is worth remembering for future use

Example: A rat hears a click from behind a partition, its mind looks for a cue that offers a hint which neurological pattern (habit) to use. The rat then knows to use the maze habit. If it hears a meow, it knows to use a different pattern. When award appears, the brain wakes up and makes sure everything is as expected.

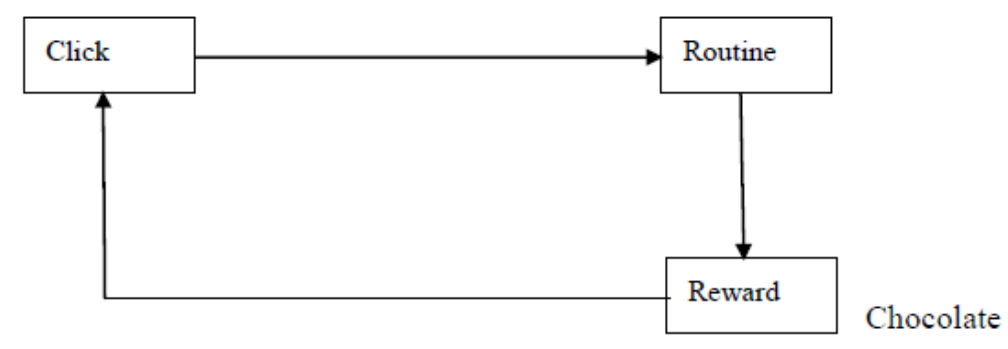

Figure 3. The Habit Loop (Model 1, Duhigg, 2012)

The researchers developed Model 2 (Fig.4) based on Duhigg's Model 1 (Fig.3) to show an example relevant to this research. Example: A talker meets a doer. The talker's brain is now looking for a cue which habit to use to engage with the doer. The talker is quite excited about this opportunity to impress the doers so it is likely that their brain will choose an emotional habit. If the doer appears to be disinterested, then the talker will use a different habit. When the award comes up such as impressing the doer successfully, the brain will make some final checks to make sure all is well and as expected by the talker. 


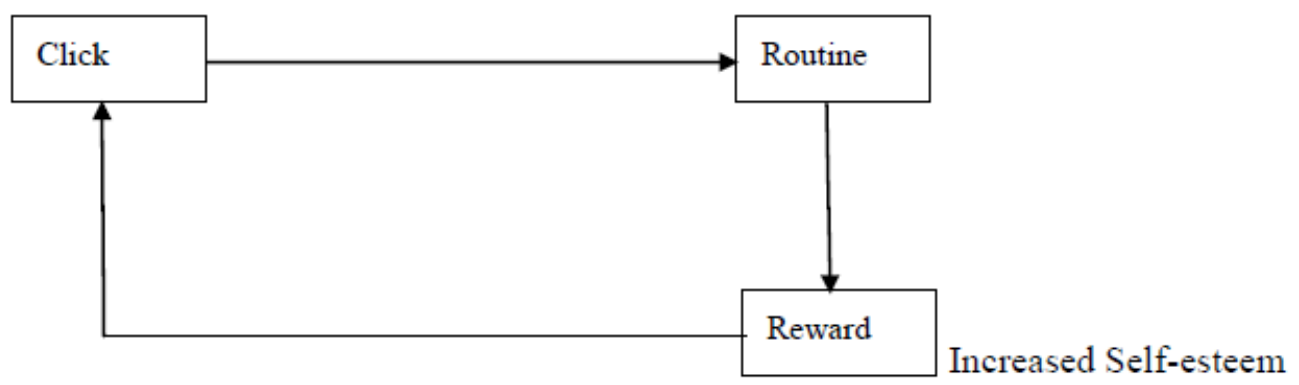

Figure 4. The Habit Loop (Model 2, based on Duhigg, 2012)

Duhigg further considers that any change in habits may not be fast but with time and effort almost any habit can be reshaped. Some habits will be more difficult to change than others. Sometimes repeated experiments and failures are required to make it work. But once a good understanding has been developed how habits operate, it is possible to gain power over it and help others to change their habits for the benefit of a more satisfying and enriched life/social life/working life. Step 1 of the Framework for Changing Habits (Fig.5, Model 3) shows that it is necessary to identify the components of the routine people wish to change. Once the habit loop of a particular behavior has been diagnosed, it is possible to look for ways to replace old habits with new routines. Step 2 suggests to experiment with different awards to understand which cravings are driving particular habits or routines. Experiments with different rewards make it possible to isolate what people are actually craving. This is essential in redesigning the habit. Step 3 considers identifying the habitual cues. These generally fit into five categories according to Duhigg: location, time, emotional state, other people and immediately preceding action. For example, to figure out the urge that drives the resulting habit, complete the five categories of 'sitting at my desk', '3-40pm', 'bored', 'no-one' and 'answered a call'. Completing this for 3 days will provide a clear understanding which cue was triggering the habit of 'buying a cookie' at a specific time. Step 4 suggests to put together an action plan to shift the behavior. By, for example, routinely talking to a colleague at around 3-40 pm for 10 minutes, it is possible to change the habit. The researchers will discuss in Chapter 4 (Discussion) how this knowledge can be used to aid talkers become doers.

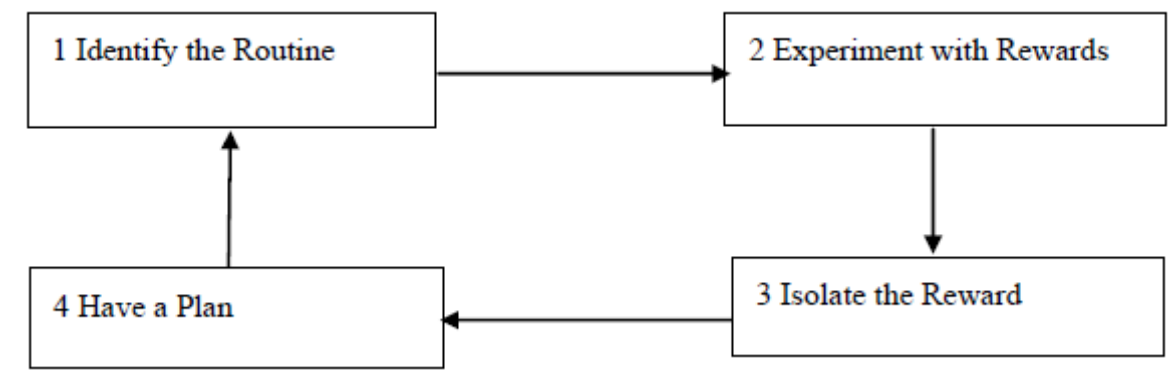

Figure 5. The Habit Loop-Final Framework for Changing Habits (Model 3, Duhigg, 2012)

According to Albohn and Adams (2016), the science of person perception has tried to capture an accurate perception of the individual and the experiences contained within individuals. 
The human face plays an important role as it provides the perceiver with vital and important information regarding, for example, the intentions, emotional state and mood of the person being perceived. It is the interactions of these cues that lead to people's impressions of others. The human face has a rich repository of complex information. It provides the perceiver with important social information. Although this so-called social vision is complex it allows people to 'read' accurate information about another person's personality. In the context of this research, it is considered possible that this could explain why many people can identify whether they are engaging with a 'Talker' rather than a 'Doer'. Continued in-depth investigation is needed in this field to build on its current advances. In contrast, Mc Naughton et al. (2016) consider that so-called approach and avoidance behaviors are fundamental to survival. The basic human brain systems have much in common with those of other species in those two specific areas. Levels of activation are influenced by genes, developmental processes and life events. 'These two systems and their associated traits can be seen as providing a foundation for the more complex processes from which mind and personality emerge' (page 25). Human approach and avoidance systems process goal representations. In the context of this research, it is possible to assume that a goal for a 'Talker' has both cognitive /identifying and motivational/consummatory properties, driven by the Talker's brain to excel at talking and impressing others by this oratory excellence. They need to be at the centre of attention. An important feature of neural systems, according to Le Deux (1994), it that they are organised in a hierarchical order. Pre-existing adaptive requirements must be fulfilled together with other sophisticated functions. As a result of an overlay of higher order circuits, this will have a direct effect of whether behaviors are slow or quick.

\subsection{Main Research Questions}

The main research questions for this research are:

1. What are the typical characteristics of talkers and doers?

2. Why and how would talkers benefit from turning words into actions?

3. Do insights gained from practical experiences (doing) outweigh insights gained from theoretical experiences (talking)?

4. How can neurological pattern changes help talkers to focus on doing rather than talking?

\section{Research Methodology}

\subsection{Method}

The researchers considered that an exegetical research approach within a constructivist interpretivist research paradigm was most appropriate to uncover thoughts and opinions. The aim of the researchers was to get close to the subject matter under investigation within the constructs of what they considered to be a socially constructed world. An associated applied lived experience qualitative research approach allowed for the inclusion of the practical real-life experiences (a posteriori) of the research participants. This strengthened the a priori knowledge from the literature review thus providing new insights into the subject matter 
under investigation. The primary focus was on ascertaining knowledge and experience, with experience being the ultimate bearer of meaning, based on what was already known about the subject matter under scrutiny. The lived experiences of the interview participants provided valuable insights from a 'life as people live it' perspective. Table 3 is a summary of the questions the research participants were asked during the formal interviews.

All answers were recorded in writing with the full approval of the students who also agreed that first names should be used to give this research more authenticity. 20 undergraduate students from the Superior Polytechnic Institute of Bié, Bié Province, Angola, were interviewed during August-September 2018. Of these 9 were female (45\%) and 11 were male (55\%). Their ages ranged from 19 years to 31 years. All students had extensive knowledge and some practical experiences in the areas of social psychology, clinical psychology and management. They provided valuable insights and valuable inspirations for further research.

Table 3. Research Questionnaire for the Face to Face Interviews

1. Based on your personal knowledge and experience, what is your definition of a person sometimes referred to as a 'Talker' and a 'Doer'? Give examples to support your answers.

2. Thinking about teachers you have interacted with in the past/present: What were the characteristics of a 'Talker'-teacher and what were the characteristics of a 'Doer'-teacher? Thinking about mangers you have interacted with in the past/present: What were the characteristics of a 'Talker'-manager and what were the characteristics of a 'Doer'-manager?

3. What would a 'Talker'-teacher need to do to become more action-oriented (do rather than talk)? What specifically would they need to do to achieve this?

What would a 'Talker'-manager need to do to become more action-oriented (do rather than talk)? What specifically would they need to do to achieve this?

4. What specific attitudes/behaviors do 'Doers' need to display to help and support 'Talkers'? Give some examples.

\subsection{Data Collection and Analysis}

The researchers considered two methods to collect relevant research data to answer the main research questions from Section 1.3: a review of the literature (Section 1.2) and face to face interviews (Section 3), within the context of a phenomenological research paradigm, an associated constructivist interpretivist research attitude and the lived experiences (life as people live it) of the interviewees. The outcome of each research method such as literature review and face to face interviews increased the contributions made to answer the research questions from Section 1.3. The findings from each of the research methods (literature review and face to face interviews) were based on evidential analysis and interpretation of all collected research data. The contemporary view contributions from the interviewees, applying an agogic approach to phenomenology, helped to stimulate balanced views based on personal insights, sensibilities and sensitivities (Van Manen, 2014). All interviews were conducted in a consistent and methodical manner. The researchers probed further from time to time when interviewees were not forthcoming with sufficient supportive evidence. The result was an increased level of data reliability and validity. The collection and analysis of the research data from this research was conducted in a controlled manner, in line with the chosen 
research method described in Section 2.1. It was thus possible to draw verifiable conclusions from it based on the validity and reliability of the research data.

Research data analysis was used continuously as the research was conducted to analyse the collected data from the two research methods of literature review and face to face interviews as soon as these were finished. Establishing what was already known about the subject matter under investigation (literature review, a priori) and then drawing in empirical data from the face to face interviews (a posteriori) was pertinent to answering the main research questions (Section 1.3). It allowed the researchers to focus their research attention working from general perspectives to more particular perspectives. Interviewees were engaged to generate new insights into what they considered would make it possible to turn a talker into a doer. The contributions of the interview participants were important to the evaluation of the research data and its contribution to the body of knowledge. Interviewees provided valid and reliable data that was used to develop considerations how talkers could become doers. Their practical and theoretical insights provided valuable perspectives of what they suggested works well in the real and commercial world managers and senior educational staff nowadays operate in (Table 4). Coding was considered inappropriate for a research article of this size and nature. The research data from the face to face interviews (41 pages, both English and Spanish) is not shown in an Appendix due to space limitations. Research participants agreed that first names should be recorded to give the research more authenticity.

\section{Results}

\subsection{Face to Face Interviews}

Based on your personal knowledge and experience, what is your definition of a person sometimes referred to as a 'Talker' and a 'Doer'? Give examples to support your answers. 'A talker shows evidence of theoretical knowledge, uses many words and as little or no ability to demonstrate practical evidence. A doer talks little, usually gets on with things and does what they say they will do' (Nelsa; Algeria; Cabral). 'A talker appears to be a good theorist but is bad when it comes to practical applications' (Angela; Rode; Isabel; Jeremiah; Manuel). 'A talker wants to be seen to be more intelligent than others, often stopping others from talking. Doers are usually quiet and just get on with things. Few words but many deeds'(Celeste; Maria; Esmeralda; Antonio).

Thinking about teachers you have interacted with in the past/present: What were the characteristics of a 'Talker'-teacher and what were the characteristics of a 'Doer'-teacher? 'Many teachers do not respond to doubts raised by some students. It appears to me that these kinds of teachers only talk and have theoretical knowledge. The doer-teacher will not only listen but also provide the students with practical applications they can relate to' (Nelsa; Martinho; Monica; Antonio; Martinha; Lazaro). 'Many teachers provide lots of guidance (talkers) but are not able to share with students how to do this practically (doer)' (Rode; Francisco). 'A talker-teacher covers too much detail in the classroom and leaves many things unexplained. A doer-teacher applies summarizing and provides relevant practical examples to support the theory' (Ermelinda; Januario). 


\section{MInstitute Machink $_{\text {Int }}$}

Thinking about mangers you have interacted with in the past/present: What were the characteristics of a 'Talker'-manager and what were the characteristics of a 'Doer'-manager? 'Managers who talk a lot and do not get much done, show evidence through their attitude and behavior, that they do not really care much about people. A doer-manager demonstrates the exact opposite: they show empathy for others and provide practical guidance to their staff. Actions speak louder than words' (Nelsa; Martinho; Monica; Januario). 'A talkative manager does not know/understand how to arrive at practical applications in relation to what they are talking about, as far as, for example, theory is concerned. In contrast, a doer-manager relates much easier to his staff, providing practical examples how to do things. They also lead by example, through their doing' (Benvindo; Rode; Francisco; Martinho; Lazaro).

What would a 'Talker'-teacher need to do to become more action-oriented (do rather than talk)? What specifically would they need to do to achieve this? 'They need to engage much more with things that relate to the reality they live in, at practical level, bringing in more feelings to strengthen their approach' (Nelsa; Francisco; Martinho; Januario). 'Good teachers should be able to talk and demonstrate the practical applications at the same time to aid students' understanding' (Algeria; Monica). 'Talker-teachers need to change their attitude and find new ways of linking theory with practice in an engaging way, and create admirable pedagogic qualities' (Maria; Isabel; Lazaro). 'Talker-teachers need to make better use of techniques, methods and strategies that allow for placing students into a kind of 'real life' situations. The objective of this is to turn young people into responsible adults by linking any theoretical content to the practical life of students. This should be done at cognitive, affective and volitional levels' (Jeremias).

What would a 'Talker'-manager need to do to become more action-oriented (do rather than talk)? What specifically would they need to do to achieve this? 'Managers should reduce how much they talk and focus their attention on providing their staff with more practical guidance what to do and how to do it' (Nelsa; Alegria; Monica; Francisco; Martinho).'Main focus of attention needs to be on the doing and the daily practice of getting things done' (Benvindo; Esmeraldo; Isabel; Jeremias). 'A talkative manager needs to overcome the obstacles of everyday life and not run away from these through talking' (Rode). 'Need to change their approach and opt more for the sharing of 'practical tools' they learned during training, for the benefit of the students' (Antonio).

What specific attitudes/behaviors do 'Doers' need to display to help and support 'Talkers'? Give some examples. 'Doers need to share their extensive experiences of how they became doers themselves and ways of achieving this' (Nelsa; Benvindo; Ermelinda). 'They need to engage talkers in such a way that they can see the benefits/values of doing more rather than just talking. Doers need to change their behaviors to make talkers feel at ease so shared experiences become learning experiences. Doers should also help talkers by being present when talkers want to demonstrate that they have changed their approach (kind of showing open and genuine support)' (Algeria; Martinho; Angela). 'Doers need to mentor and coach talkers so the talkers learn how to do more and how to say less' (Celeste; Maria; Isabel). 'Talkers need to be shown by doers that the linking of theory and practice has 
enormous benefits. Doers need to encourage talkers by leading by example. They need to create higher levels of self-belief and self-confidence in talkers by creating an environment of authentic help and support' (Francisco; Esmeraldo; Jeremias; Januario).

A brief summary of the application and the ranking of considered solutions of how talkers can become doers, based on the analysis of data from this research, is shown at Table 4 .

Table 4. From Talking to Doing-Application and Ranking of Considered Solutions

\begin{tabular}{|c|c|c|}
\hline Skills & Application & Ranking \\
\hline $\begin{array}{l}\text { Visual } \\
\text { Perceptions }\end{array}$ & $\begin{array}{l}\text { Developing an ability to interpret the faces of others (visual information) } \\
\text { will help talkers to establish accurately what people really are like and } \\
\text { what experiences they hold, and make judgements who to adopt (doer) as } \\
\text { a role model }\end{array}$ & $\begin{array}{l}\text { Considered } \\
\text { important by the } \\
\text { literature review }\end{array}$ \\
\hline $\begin{array}{l}\text { Social } \\
\text { Information }\end{array}$ & $\begin{array}{l}\text { Identify, for example, the social status, occupation, age and gender of } \\
\text { individuals and group them together }\end{array}$ & $\begin{array}{l}\text { Considered } \\
\text { important by the } \\
\text { literature review }\end{array}$ \\
\hline $\begin{array}{l}\text { Motivation, } \\
\text { Drive and } \\
\text { Success }\end{array}$ & $\begin{array}{l}\text { Develop self-beliefs of being worthy of success and higher levels of } \\
\text { motivation that direct, energize and make people more determined to } \\
\text { do/achieve something such as changing from being a talker to becoming } \\
\text { a doer }\end{array}$ & $\begin{array}{l}\text { Identified by all } \\
\text { parties as being } \\
\text { important* }\end{array}$ \\
\hline $\begin{array}{l}\text { Attitudes and } \\
\text { Behaviors }\end{array}$ & $\begin{array}{l}\text { Disable attitudes and behaviors that hinder positive and pro-active } \\
\text { actions to foster self-beliefs and high levels of motivation to change }\end{array}$ & $\begin{array}{l}\text { Identified by all } \\
\text { parties as being } \\
\text { important } *\end{array}$ \\
\hline $\begin{array}{l}\text { Habits and } \\
\text { Routines }\end{array}$ & $\begin{array}{l}\text { Understand better what the disabling inactions (such as anger, depression } \\
\text { and distrust) and self-sabotaging actions of individuals are and deal with } \\
\text { them for personal advantage and to progress }\end{array}$ & $\begin{array}{l}\text { Identified by all } \\
\text { parties as being } \\
\text { important } *\end{array}$ \\
\hline Focus and Flow & $\begin{array}{l}\text { To perform at their best and become creative and fearless of change, } \\
\text { individuals need to make better use of tools they already have, in areas } \\
\text { such as time management, consistency and logic }\end{array}$ & $\begin{array}{l}\text { Considered } \\
\text { important by the } \\
\text { literature review }\end{array}$ \\
\hline $\begin{array}{l}\text { Good Balance } \\
\text { and Relaxation } \\
\text { Level }\end{array}$ & $\begin{array}{l}\text { The ability to clear the mind and being flexible is potentially a panacea to } \\
\text { achieving desired results and outcomes. Thinking about outcomes is a } \\
\text { very effective way of turning goals into reality }\end{array}$ & $\begin{array}{l}\text { Considered } \\
\text { important by the } \\
\text { literature review }\end{array}$ \\
\hline $\begin{array}{l}\text { Human Brain } \\
\text { Engagement }\end{array}$ & $\begin{array}{l}\text { Providing individuals with opportunities to do, for example, new things, } \\
\text { also provides opportunities to make mistakes, and thus gaining new } \\
\text { insights. Talkers can change by doing more, making mistakes and } \\
\text { growing as a person, including developing higher levels of } \\
\text { self-confidence }\end{array}$ & $\begin{array}{l}\text { Identified by all } \\
\text { parties as being } \\
\text { important } *\end{array}$ \\
\hline Values & $\begin{array}{l}\text { Gain an understanding of what is important and of value to other people. } \\
\text { It is then possible to predict their behaviors, stress and frustration when } \\
\text { these values are challenged. Doers and talkers, for example, would then } \\
\text { be in a good position to adjust their way of doing things and become } \\
\text { more attuned to each other }\end{array}$ & $\begin{array}{l}\text { Identified by all } \\
\text { parties as being } \\
\text { important } *\end{array}$ \\
\hline
\end{tabular}


\begin{tabular}{|l|l|l|l|l}
\hline Mentoring & Talkers would benefit from being mentored by trustworthy and & Identified by all
\end{tabular} respectable doers. Insights from new experiences such as doing rather parties as being than talking would assist talkers to change their habits/routines long term important* and increase their levels of self-confidence

\begin{tabular}{l|l} 
Person & Both talkers and doers need to develop an ability to recognize and apply
\end{tabular} Considered

Perception

'approach and avoidance' behaviors to interact successfully with each other. Due to some higher neurological circuit order in the human brain, important by the this explains why some behaviors are slow and other are fast

*Literature review and Face to Face interviews

\section{Discussion}

The importance of organizational behavior is increasing in importance in today's working environments. Many companies and institutions have recognised that it is necessary for them to optimize their organizational behavior in areas such as managing effective teams/individuals and understanding/predict human behavior. Employees not only have to deliver their own work targets but also have to work together with others to achieve set and expected team goals and objectives. The ultimate aim appears to be the creation of more efficient organizations that can optimize their modus operandi at the human level. This means that every employee needs to feel, think and operate at their best and make expected contributions to support the organizations they are working for achieve their corporate business targets.

The researchers who have more than 60 years of practical lived work experience in industries such as Education, Telecommunications and Defence between them, suggest that there are two types of people at work: those who talk a lot but never get much done and those who do a lot and talk relatively little. The outcome of this research has confirmed that the phenomena of talking and doing have been around for quite some time and yet shortfalls still appear to exist between actions organizations take to increase organizational behavior levels and the contributions made by the people they employ. It is possible for organizations to close this shortfall by focusing their attention on turning talkers into doers.

Talkers appear to find many reasons why something cannot be done whereas doers look for and find reasons why something can be done. To convert talkers to doers, companies and educational institutions need to create working environments in which talkers are openly encouraged, and can safely practise, without repercussions, the adoption of new attitudes and associated behaviors, leading to desired and repetitive behaviors that ultimately turn talkers into doers for the right and genuine/authentic reasons, and also enhance the organizational behavior of who they work for, leading to higher performance levels, mutual trust and a positive thinking culture. This paper suggests that a desirable outcome to turn talkers into doers is to get talkers to develop their own new 'doing' behaviors and then experience the positive outcomes of this (Skinner, 2012). It is then considered to be more likely that talkers will repeat these behaviors as they have lived experience of the actual benefits of having changed previous behaviors. Talkers need to be encouraged by line management to remove negative stimuli from past behaviors, disturbing the process of doing, with positive reinforced 
lived behaviors that lead to increases in that behavior.

The outcome of the literature review suggests some approaches talkers could adopt to learn more about what it means to be a doer. For example, improving inaccuracies in their perception of others would help talkers avoid misinterpreting outputs from discussions with doers, thus reducing the threat to react eccentrically to these and remaining in control. The identification and interpretation of non-verbal behaviors is of equal importance. Behaviors are overt and understanding how others feel, what they believe in and what they wish to have can help talkers to review and change their own behaviors so they focus their attention on behaviors that are associated with people who do what they say they are going to do (doers).

It appears that talkers are not in a constant reality-like state. It is possible for talkers to create this state in their efforts to switch from dreaming to doing. It requires concentrated efforts and includes seeing the value of turning dreams into tangible goals to achieve desired outcomes. Combining this high level of focus with lived experiences is a very powerful combination that can help talkers turn into extraordinary doers. In contrast, the results from the face to face interviews indicate that it is considered possible for talkers to change in order to become more action-oriented.

Engaging closely with doers and asking them to share their lived experiences appears to be a potential way forward. Understanding and knowing how people developed into becoming doers and how this was achieved, will help even the most habitual talkers to convert as long as they see the benefits for them of doing so. Irrespective of the industry people operate or work in, creating working environments where talkers are respected for what they are and where learning is encouraged, will positively help the transformation process by putting talkers more at ease in order to support the planned change.

\section{Conclusions}

Talkers cannot change to become doers without the help and support from others such as action-centred people they work with, for example, and the organizations they work for. A considerable amount of effort is required by all parties to make this happen. It needs to be approached by focusing on the right and genuine reasons for doing so. Influencing talkers by selling them the benefits why they should change is an absolute pre-requisite and an excellent starting point.

At personal level, talkers will become more self-confident in their actual abilities and will not require close supervision in future. Performance levels will increase proportionate to increases in motivation. These are directly allied to higher levels of self-confidence, needed to gain the confidence of others and essential for individuals to succeed whatever they wish to succeed in. Talker-teachers who work in the educational industry, need to develop new approaches to teaching and interacting with students. For example, they need to enhance the learning experiences of their students by providing more practical application examples based on their own lived experiences that underpin the taught theory. Students would benefit from doer-teachers who display higher levels of emotional and motivational stimulations and who can demonstrate positive self-beliefs based on lived practical experiences that complement 
theory.

Stronger individuals make for stronger teams. Improved team performance is the potential result. Talkers who become doers are more likely to be in a fit state to meet the ever-changing business challenges organizations face in future. From an organizational perspective, investing in talkers to become doers should be viewed as a long-term investment rather than a short-term fix. Creating a work force that is made up of people who are action-focused can act as an enabler to make it possible to put organizations into favourable business positions by optimizing people's competence levels at both individual and team levels. A higher rate of social return on investment in non-fiscal terms (and costs) can be expected relative to the investment in human resources. The acquisition of new skills requires organizational staff to change their attitudes towards these changes and organizations themselves should focus their attention not on the actual behaviors but what it is these behaviors will actually achieve.

This research was limited to theoretical and lived experience from 20 undergraduate students from the Superior Polytechnic Institute, Bie Province, Angola . It would have been valuable to collect the contemporary inputs from students from other countries to assess whether the conclusions from this research could be universally applied. It is confirmed that the research questions from Section 1.3. have been answered (Section 5: Conclusions).

\section{Acknowledgements}

The corresponding author wishes to thank the Universidad de Oriente in Santiago de Cuba and the Superior Polytechnic Institute in Bie Province, Angola, for providing access to interview students from the Faculty of Business and Management Studies (SPI) and making time available for the production, collection and submission of the interview research data for use by the researchers.

\section{References}

Albohn, D. N., \& Adams, R. B. (Jnr.) (2016). Social Vision: At the Intersection of Vision and Person Perception, In J.R. Absher \& J. Cloutier (Eds.) Neuroimaging Personality, Social Cognition, and Character, 159-186, San Diego, CA, US: Elsevier Academic Press, http://dx.doi.org/10.1016/B978-0-12-800935-2.00008-7

Allen, D. (2001). Getting Things Done-How to Achieve Stress-free Productivity, Piatkus, Reprinted 2014.

Ambady, N., Bernieri, F. J., \& Richeson, J. A. (2000). Toward a histology of social behavior: judgmental accuracy from thin slices of the behavioral stream, In: Advances in Experimental Social Psychology, 32, 201-271, San Diego, CA: Academic Press

Clutterbuck, D. (1998). Learning Alliances, IPD

Clutterbuck, D. (1991). Everyone Needs a Mentor, Second Edition, Pub Institute of Personnel and Development.

Crisp, R. J., \& Turner, R. N. (2010). Essential Social Psychology, Second Edition, Sage Publications Ltd., https://doi.org/10.1111/j.1529-1006.2004.00018.x 
Dilts, R. (1990). Changing Belief Systems with Neuro-Linguistic Programming (NLP), Capitola, CA: Meta Publications

Duhigg, C. (2012). The Power of Habit-Why we do what we do and how to change, Random House Books

Fisher, E., \& Santana, G. Y. (2017). Increasing Brain Power beyond Imagination-Aligning Neuroscience and Social Psychology to Aid Prevention, Business and Economic Research, 7(2), 82-101, https://doi.org/10.5296/ber.v7i2.11301

Fisher, E., \& Santana, G. Y. (2013). The ABC Manager-How to Manage People more Effectively in Today's Challenging and Demanding Work Environments, Engineering Management Research, 2(1), 67-78. https://doi.org/10.5539/emr.v2n1p67

Freeman, J. B., \& Ambady, N. (2011). A dynamic interactive story of person construal, Psychol Rev, 118, 247-279, https://doi.org/10.1037/a0022327

Gibson, J. J. (1979). The Ecological Approach to Visual Perception, Boston: Houghton Mifflin

Gill, R. (2011). Theory and Practice of Leadership, Second Edition, Sage

Goleman, D. (2007). Motivation, Edina, MN: Adams Business

Goleman, D. (1998). Working with Emotional Intelligence, London: Bloomsbury

Goleman, D. (1995). Emotional Intelligence, London: Bloomsbury

Johnson, M. H., \& de Haan, M. (2015). Developmental Cognitive Neuroscience. Fourth Edition, Wiley Blackwell

Kelsey, R. (2014). Get Things Done-What stops smart people achieving more and how you can change, Capstone-A Wiley Brand.

Klein, G. (2014; 2017). Seeing What Others Don't-The Remarkable Ways We Gain Insights, Nicholas Brealey Publishing

Le Deux, J. E. (1994). Emotions, memory and the brain, Scientific American, 270, 50-59. https://doi.org/10.1038/scientificamerican0694-50

Macrae, C. N., \& Bodenhausen, G. V. (2000). Social Cognition: thinking categorically about others, Ann Rev Psychol, 51, 93-120, https://doi.org/10.1146/annurev.psych.51.1.93

Mc Aleer, P., Todorov, A., \& Belin, P. (2014). How do you say 'hello'? Personality impressions from brief novel voices, PLOS ONE, 9(3),

https://doi.org/10.1371/journal.pone.0090779

Mc Naughton, N., DeYoung, C. G., \& Corr, P. J. (2016). Approach/Avoidance, Neuroimaging $\begin{array}{llll}\text { Personality, Social Cognition and } & \text { Character, } & \text { 25-49. }\end{array}$ https://doi.org/10.1016/B978-0-12-800935-2.00006-3

Maio, G. R., \& Haddock, G. (2010). The Psychology of Attitudes and Attitude Change, Sage Publications Ltd. 


\section{Macrothink}

Business and Economic Research ISSN 2162-4860 2018, Vol. 8, No. 4

Mitchell, J. P., Banaji, M. R., \& Macrae, C. N. (2005). General and specific contributions of the medial prefrontal cortex to knowledge about mental states, NeuroImage, 28, 757-762 https://doi.org/10.1016/j.neuroimage.2005.03.011

Oosterhof, N. N., \& Todorov, A. (2008). The functional basis of face evaluation, Proc Natl Acad Sci, 105, 11087-11092. https://doi.org/10.1073/pnas.0805664105

Owen, H. (2011). The Complete Guide to Mentoring-How to design, implement and evaluate effective mentoring programmes, Kogan Page

Quest (1997). Be Your Best, Readymade Tools for Personal Development, edited by Steve Smith, Quest Toolbox Series

Skinner, B. F. (2012). In 'Big Ideas Simply Explained', The Psychology Book, 78-85, Dorling Kindersley Ltd.

Stolier, R. M., \& Freeman, J. B. (2016). The Neuroscience of Social Vision, Neuroimaging Personality, Social Cognition and Character, 7, 139-157, Elsevier Publishing Ltd. https://doi.org/10.1016/B978-0-12-800935-2.00006-3

Van Manen, M. (2014). Phenomenology of Practice-Meaning-Giving Methods in Phenomenological Research and Writing, Routledge

Walls, G. (1926). The Art of Thought, New York: Harcourt, Brace

Zebrowiz, L. A. (1997). Reading Faces: Window to the Soul?, New Directions in Social Psychology.

\section{Copyright Disclaimer}

Copyright for this article is retained by the author(s), with first publication rights granted to the journal.

This is an open-access article distributed under the terms and conditions of the Creative Commons Attribution license (http://creativecommons.org/licenses/by/3.0/). 